\title{
Anesthetic Management and Perioperative Events of Peripartum Cardiomyopathy during Cesarean Delivery a Series of Five Cases
}

\author{
Sree Rama Chandra Murthy Mellacheruvu ${ }^{1} \quad$ Kousalya Chakravarthy $^{1} \quad$ Khaliq Ahmed $^{1}$ \\ ${ }^{1}$ Department of Anaesthesia, MGMH Petlaburz, Osmania Medical \\ Corresponding Author Kousalya Chakravarthy, MD, DGO, 3-5-1083, \\ College, Hyderabad, Telangana, India \\ Flat 306, Sri Tara Jeet Residency, Narayanguda,Hyderabad, 500029, \\ Telangana, India (e-mail: dr.kausi.c@gmail.com).
}

Indian J Cardiovasc Dis Women-WINCARS 2018;3:198-203

\begin{abstract}
Peripartum cardiomyopathy (PPCM) is a rare idiopathic cardiomyopathy having an incidence of less than $0.1 \%$. PPCM is associated with high morbidity and mortality rates ranging from 5 to $32 \%$. In this review, the authors report a series of five PPCM cases. The case reports included pregnant women with PPCM, admitted in the hospital from October 1, 2017 to June 1, 2018 over a period of 9 months who required cesarean section. The authors aim to discuss the presentation, optimization, anesthetic management, and postoperative care of this rare condition. One of the cases was a booked case. The remaining four pregnant patients were referred in late pregnancy with features of congestive cardiac failure. One patient was in acute pulmonary edema, required intubation, and subsequently had cesarean section under general anesthesia. Four patients were managed with incremental epidural anesthesia. The need for proper preoperative optimization and intra- and postoperative management was discussed.

Keywords

- anesthesia

- cardiomyopathy

- epidural

- general anesthesia The authors had one maternal mortality in our series. There was no neonatal mortality. Early diagnosis of PPCM, prompt treatment of heart failure, planning the delivery, and postpartum care can decrease maternal morbidity and mortality. Incremental epidural dosing can be used for cesarean section and has the advantage of stable hemodynamic status without the risks associated with general anesthesia.
\end{abstract}

\section{Introduction}

Peripartum cardiomyopathy (PPCM) by definition is "an idiopathic cardiomyopathy presenting with heart failure secondary to left ventricular systolic dysfunction towards the end of pregnancy or in the months following delivery, where no other cause of HF is found." ${ }^{\text {PPCM }}$ is a diagnosis of exclusion. The incidence of PPCM is less than $0.1 \%$ of pregnancies. ${ }^{2}$ The following criteria define PPCM ${ }^{3}$ : (1) heart failure (HF) in the last 5 weeks of pregnancy or up to 5 months postpartum, (2) lack of other recognizable causes of cardiac failure, and (3) left ventricular (LV) dysfunction, as defined by an ejection fraction (EF) less than $45 \%$ (the left ventricle may or may not be dilated). Prognosis depends on the extent of LV dysfunction as assessed by the echocardiographic (echo) findings and the New York Heart Association (NYHA) functional class.
PPCM is associated with high morbidity and mortality rates ranging from 5 to $32 \%{ }^{3,4}$

\section{Aim}

In this report, we present a series of five PPCM cases. We aim to discuss the presentation, optimization, anesthetic management, and postoperative care of this rare condition.

\section{Methodology}

This review is an analysis of five PPCM cases admitted to a public sector tertiary care center for obstetrics, for further management. The report included pregnant women with PPCM admitted to the hospital, from October 1, 2017 to June 1,2018 over a period of 9 months. 


\section{Case Report}

\section{Case 1}

A 29-year-old gravida (G) 4, para (P) 3, live (L) 3, at 36 weeks of gestation was referred with shortness of breath (SOB). At the time of admission, the patient was acutely dyspneic and hypoxic. She was afebrile and had a blood pressure (BP) of 156/88 mm Hg, a pulse rate (PR) of 154 beats/min, a respiratory rate (RR) of 45 breaths/min, and an oxygen saturation of $75 \%$ on oxygen $5 \mathrm{~L}$ with facemask. On auscultation, she had bilateral coarse crepitations. She was admitted to the intensive care unit (ICU), with a diagnosis of acute pulmonary edema. Her medical history revealed history of PPCM in the previous pregnancy on second postoperative day (POD) after lower-segment cesarean section (LSCS). On admission a transthoracic two-dimensional (2D) echo was done, which revealed left atrial and LV dilatation, global LV hypokinesia, and EF of 25 to 30\%. Electrocardiogram (ECG) showed sinus tachycardia. In view of acute pulmonary edema with respiratory failure, the patient was intubated with suxamethonium and connected to ventilator with positive end-expiratory pressure (PEEP) of $8 \mathrm{~cm} \mathrm{H}_{2} \mathrm{O}$. Intubation response was minimized with fentanyl $100 \mu \mathrm{g}$, midazolam $2 \mathrm{mg}$, Xylocard $80 \mathrm{mg}$, and careful titration of propofol. Fetal monitoring was done with cardiotocography (CTG). Termination of pregnancy by LSCS after initial maternal stabilization was decided. Preoperative optimization was done with repeated boluses of frusemide, head-up position, $100 \%$ oxygen, and PEEP. Heart rate was controlled with guarded doses of intravenous (IV) metoprolol. Two hours after stabilization, the patient was taken up for emergency LSCS under general anesthesia. Intraoperative monitoring was standard for cardiac diseases of pregnancy and included pulse oximetry, continuous ECG, invasive BP monitoring, and right internal jugular vein (IJV) cannulation. Urine output was monitored with bladder catheterization. The intraoperative management as per the management of cardiac diseases of pregnancy included restricted IV fluids, with noradrenaline and nitroglycerine (NTG) backup, exaggerated left uterine displacement (LUD), opioid fentanyl $100 \mu \mathrm{g}$ IV after baby delivery, and frusemide $40 \mathrm{mg}$ IV bolus after baby delivery. Oxytocics included oxytocin as infusions at $5 \mathrm{U} / \mathrm{h}$ and misoprostol 1,000 $\mathrm{mg}$ (prostaglandin E1 $\left.\left[\mathrm{PGE}_{1}\right]\right)$ rectal suppository. Prophylactic B-lynch compression sutures were applied to the uterus. Intraoperative vitals were maintained, and the patient was shifted to ICU for elective ventilation and extubated after 24 hours. Postoperative pain relief was given by IV infusion of fentanyl at $10 \mu \mathrm{g} / \mathrm{h}$, with IV paracetamol every 6 hours. Postoperative care included head-up position, frusemide $40 \mathrm{mg}$ IV 8th hourly, angiotensin-converting enzyme inhibitor (ACE-I) enalapril $2.5 \mathrm{mg}$ once a day, oral Metoprolol $12.5 \mathrm{mg}$ 12th hourly, and fluid restriction to $75 \mathrm{~mL} / \mathrm{h}$ of crystalloid. Postoperative pulmonary complications (POPC) were prevented by nebulization, deep breathing exercises, chest physiotherapy, and deep vein thrombosis (DVT) prophylaxis with low-molecular-weight heparin (LMWH) enoxaparin $40 \mathrm{mg}$ once in 24 hours. The patient had an uneventful recovery, and she and her baby were discharged in hemodynamically stable condition for further cardiologist's review and follow-up.

\section{Case 2}

A G2P1L1 at 37 weeks of gestation with previous LSCS was referred with acute onset of dyspnea in active labor. Her previous pregnancy was uneventful. The patient was a known asthmatic. At the time of presentation, she was tachypneic with an RR of 28 breaths/min. Oxygen saturation was $92 \%$ with 6 L of oxygen on facemask. Her noninvasive blood pressure (NIBP) was 120/80 and heart rate was 114 beats/min. On auscultation bilateral wheeze and basal crepitations were present. Two-dimensional echo showed global hypokinesia and 35\% left ventricular ejection fraction (LVEF). ECG showed sinus tachycardia. Preoperative optimization was started with frusemide, ivabradine $5 \mathrm{mg}$ for rate control, levo-salbutamol, and budesonide nebulizations for wheeze. As the patient was in active labor, after initial stabilization, emergency LSCS was done under epidural anesthesia with monitored incremental doses of local anesthetic with opioid fentanyl. Instead of contemplating a rapid-sequence induction in a pregnant asthmatic with wheeze, we preferred incremental epidural anesthesia, taking care not to cause hemodynamic compromise. Intraoperative monitoring, fluid input, and oxytocic dosing were done as per our standard management of cardiac diseases of pregnancy. The patient was shifted to ICU in hemodynamically stable condition. Six hours after the surgery, she became dyspneic and started desaturating. Initially noninvasive ventilation (NIV) was tried, but the patient had to be intubated and noradrenaline support was started due to fall in the BP and she was referred to cardiology department for further management. The patient succumbed on third POD.

\section{Case 3}

A G2P1L1 with term gestation was referred in view of previous history of PPCM detected on second POD of previous pregnancy. At the time of presentation, the patient was dyspneic with an RR of 20 breaths/min, BP of 140/90 mm $\mathrm{Hg}$, and $\mathrm{SpO}_{2}$ of $94 \%$ on room air. On auscultation, there were decreased breath sounds bilaterally. Two-dimensional echo showed global hypokinesia and 35 to 40\% LVEF. Trivial mitral regurgitation (MR) and trivial aortic regurgitation (AR) were present. ECG showed sinus tachycardia. Preoperative optimization was done with frusemide and ivabradine $5 \mathrm{mg}$ once in 24 hours. After optimization and stabilization of the condition, the patient was posted for elective LSCS under incremental epidural anesthesia. Intraoperative cardiac monitoring was done. Both intraand postoperative periods were uneventful.

\section{Case 4}

A G2P1L1 at 37 weeks of gestation with breech was referred in view of PPCM. PPCM was detected when the patient was evaluated for dyspnea and easy fatigability. Two-dimensional echo showed global akinesia, 40\% LVEF, and mild MR. ECG 
showed sinus tachycardia. The patient was started on ivabradine $5 \mathrm{mg}$ for rate control and spironolactone. Elective LSCS was done under incremental epidural anesthesia. Both intra- and postoperative periods were uneventful.

\section{Case 5}

A G3P2L2D1 with term gestation with previous history of PPCM with severe preeclampsia, hemolysis, elevated liver enzymes low platelet (HEELP) syndrome, acute kidney injury (AKI), severe LV dysfunction, and PPCM was referred for institutional delivery. At the time of presentation, the patient was physically and hemodynamically stable with no symptoms of PPCM or HF. Her laboratory parameters in the present pregnancy were normal. However, 2D echo showed global hypokinesia and LVEF less than 45\%. LSCS was done under incremental epidural anesthesia uneventfully. Postoperatively the patient was monitored in ICU and had an uneventful recovery.

\section{Observation}

All the five patients presented in the third trimester. The chief presenting complaint was SOB (-Table 1). Preoperative investigations included complete blood count, liver function tests, renal function tests, complete urine examination, thyroid profile, and transthoracic echocardiograph. The baseline blood investigations were normal in all the five cases. The risk stratification was done taking into consideration the American Society of anesthesiologists (ASA) grading, ${ }^{5}$ New York Heart Association (NYHA) class, ${ }^{6}$ Cardiac Disease in Pregnancy (CARPREG) score, and World Health Organization (WHO) classification of cardiac disease in pregnancy. ${ }^{7}$ All the five cases were high risk with
ASA grade III to IV E and NYHA grade III to IV. WHO and CARPREG scores too were suggestive of increased risk of major adverse cardiac events (MACE) ( - Table 2 ).

Anesthetic management was done by incremental epidural dosage in four out of the five cases, whereas one required mechanical ventilation for acute pulmonary edema and was continued as general anesthesia for cesarean delivery. Post-delivery, the patients were started on medications for HF titrated to the individual needs. All the patients were started on ACE-I enalapril 2.5 to $5 \mathrm{mg}$, sustained-release metoprolol or carvedilol or ivabradine $5 \mathrm{mg}$ for rate control, and a diuretic spironolactone $25 \mathrm{mg}$ and/or frusemide. POPCs were prevented by head-up position, nebulization, deep breathing exercises, chest physiotherapy, and DVT prophylaxis with LMWH enoxaparin $40 \mathrm{mg}$ once in 24 hours. Early liquid diet was resumed in the last three cases.

\section{Discussion}

Peripartum cardiomyopathy may present as $\mathrm{HF}$ in pregnant women. Viral infections, selenium deficiency, autoimmunity, and genetic predisposition are some of the factors predisposing to PPCM. $^{8}$ Advanced maternal age, multiple gestation, chronic hypertension, and assisted reproductive techniques may contribute to the increased incidence. Recently the role of Fms-like tyrosine kinase 1 (sFlt-1) and the hormone prolactin in PPCM is being evaluated. ${ }^{8}$ Awareness of the condition, early echocardiography, availability of obstetric anesthesia, and critical care services improved the outcome in this rare condition.

Typically, patients become symptomatic after 36weeks of gestation or within the first month of delivery. ${ }^{9}$ Worldwide

Table 1 Condition at the time of admission

\begin{tabular}{|c|c|c|c|c|c|c|c|c|}
\hline $\begin{array}{l}\text { Case } \\
\text { number }\end{array}$ & $\begin{array}{l}\text { Pregnancy } \\
\text { status }\end{array}$ & $\begin{array}{l}\text { Previous } \\
\text { PPCM }\end{array}$ & $\begin{array}{l}\text { Presenting } \\
\text { complaint }\end{array}$ & $\begin{array}{l}\text { PR } \\
\text { (beats/ } \\
\text { min) }\end{array}$ & $\begin{array}{l}\text { BP } \\
(\mathrm{mm} \\
\mathrm{Hg})\end{array}$ & $\begin{array}{l}\text { RR (breaths/ } \\
\text { min) }\end{array}$ & Lungs & Present diagnosis \\
\hline 1 & $\begin{array}{l}\text { G4P3L3 } \\
36 \text { wk }\end{array}$ & $\begin{array}{l}\text { Previous } \\
\text { LSCS } \\
\text { Postpar- } \\
\text { tum PPCM }\end{array}$ & SOB & $155-165$ & $140 / 90$ & $38-40$ & $\begin{array}{l}\text { Bilateral } \\
\text { coarse } \\
\text { crepitations }\end{array}$ & $\begin{array}{l}\text { APO } \\
\text { PPCM }\end{array}$ \\
\hline 2 & $\begin{array}{l}\text { G2P1L1 } \\
37 w k\end{array}$ & $\begin{array}{l}\text { Previous } \\
\text { LSCS }\end{array}$ & SOB & 94 & $120 / 80$ & 28 & $\begin{array}{l}\text { Bilateral } \\
\text { diffuse } \\
\text { wheeze }\end{array}$ & PPCM \\
\hline 3 & $\begin{array}{l}\text { G2P1L1 } \\
38 w k\end{array}$ & $\begin{array}{l}\text { Previous } \\
\text { LSCS } \\
\text { Postpar- } \\
\text { tum PPCM }\end{array}$ & $\begin{array}{l}\text { SOB, easy } \\
\text { fatigability }\end{array}$ & 110 & $140 / 90$ & 28 & $\begin{array}{l}\text { Decreased } \\
\text { air entry in } \\
\text { the bases }\end{array}$ & $\begin{array}{l}\text { PPCM with early } \\
\text { decompensation }\end{array}$ \\
\hline 4 & $\begin{array}{l}\text { G2P1L1 } \\
38 \text { wk } \\
\text { breech }\end{array}$ & $\begin{array}{l}\text { PPCM now } \\
\text { Previous } \\
\text { LSCS }\end{array}$ & $\begin{array}{l}\text { SOB, easy } \\
\text { fatigability }\end{array}$ & 124 & $110 / 80$ & 30 & BAEE & PPCM \\
\hline 5 & $\begin{array}{l}\text { G3P2L2D1 } \\
38 \text { wk }\end{array}$ & $\begin{array}{l}\text { Postpar- } \\
\text { tum PPCM } \\
\text { Previous } \\
\text { LSCS }\end{array}$ & $\begin{array}{l}\text { Institution- } \\
\text { al delivery }\end{array}$ & 86 & $140 / 90$ & 18 & BAEE & PPCM \\
\hline
\end{tabular}

Abbreviations: APO, acute pulmonary edema; BAEE, bilateral air entry equal; BP, blood pressure; G, gravida; L, live; LSCS, lower-segment cesarean section; P, para; PPCM, peripartum cardiomyopathy; PR, pulse rate; RR, respiratory rate; SOB, shortness of breath. 
Table 2 Risk stratification

\begin{tabular}{|c|c|c|c|c|c|c|c|}
\hline \multirow{2}{*}{$\begin{array}{l}\text { Case } \\
\text { number }\end{array}$} & \multirow[t]{2}{*}{ ASA } & \multirow[t]{2}{*}{ NYHA } & \multirow[t]{2}{*}{ WHO } & \multicolumn{2}{|c|}{ CARPREG } & \multirow[t]{2}{*}{$\mathrm{EF}(\%)$} & \multirow[t]{2}{*}{ Morbidity/Mortality } \\
\hline & & & & Score & MACE (\%) & & \\
\hline 1 & IVE & IV & IV & $>1$ & 75 & $25-30$ & $\begin{array}{l}\text { Pulmonary edema, mechanical ven- } \\
\text { tilation, emergency LSCS, ICU stay }\end{array}$ \\
\hline 2 & $\mathrm{I}-\mathrm{II} \mathrm{E}$ & III & IV & $>1$ & 75 & 35 & $\begin{array}{l}\text { Wheeze, emergency LSCS, post- } \\
\text { partum heart failure, mechanical } \\
\text { ventilation, shifted to cardiology } \\
\text { department; succumbed on } 2 \text { nd } \\
\text { POD }\end{array}$ \\
\hline 3 & III & III & IV & $>1$ & 75 & $35-40$ & ICU admission and optimization \\
\hline 4 & III & II-III & II-III & 1 & 27 & 40 & ICU admission and optimization \\
\hline 5 & III & II & IV & 1 & 27 & $<45$ & $\begin{array}{l}\text { Regular antenatal care, cardiologist } \\
\text { follow-up, anesthetic evaluation } \\
\text { and plan }\end{array}$ \\
\hline
\end{tabular}

Abbreviations: ASA, American Society of Anesthesiologists; CARPREG, Cardiac Disease in Pregnancy; E (suffix), emergency; EF, ejection fraction; ICU, intensive care unit; LSCS, lower-segment cesarean section; MACE, major adverse cardiac events; NYHA, New York Heart Association; POD, postoperative day; WHO, World Health Organization (classification of cardiac disease in pregnancy).

registry on PPCM reported that $21 \%$ of women with PPCM had cardiomyopathy in a previous pregnancy. ${ }^{3}$ The presenting symptom in most patients is dyspnea on exertion (NYHA-III or IV). Some may present with complex arrhythmias or peripheral or pulmonary embolic episodes or cardiac arrest.

For the evaluation of PPCM, apart from ECG and echo, complete blood cell count, blood urea, creatinine, electrolytes, liver function test, and thyroid-stimulating hormone should be done. Echo findings consistent with PPCM include a decreased ejection fraction, global dilatation, and thinned-out cardiac walls. ${ }^{10}$ Brain natriuretic peptide (BNP) or $\mathrm{N}$-terminal pro-brain natriuretic peptide (NTproBNP) levels have high sensitivity in HF. NTproBNP levels of $100 \mathrm{pg} / \mathrm{mL}$ or less have a high negative predictive value for adverse maternal events and can be helpful to screen potential PPCM. ${ }^{10}$ Cardiac magnetic resonance imaging can be a complementary tool in the diagnosis and further evaluation of PPCM women. ${ }^{11}$

In this case series, four out of the five patients presented with dyspnea after 36 weeks of gestation. Four out of the five patients had a history of previous PPCM. All the five PPCM cases in this case series had an $\mathrm{EF}$ of less than $45 \%$.

Management of PPCM is the same as that of cardiac failure of other etiologies. Acute management is the management of airway, breathing, and circulation (ABCs). Acute decompensation presenting as acute pulmonary edema adds to the difficult airway in pregnant women. The decreased functional residual capacity (FRC) and the increased oxygen demand in pregnancy can lead to rapid desaturation, hypoxia, and maternal acidosis. Maternal desaturation can lead to fetal compromise, putting both lives at peril. Hence oxygen supplementation is of paramount importance. Although a relative contraindication in pregnancy, NIV, when used judiciously, can obviate the need for endotracheal intubation. Hypoxia, respiratory failure, and hypotension mandate endotracheal intubation and mechanical ventilator support. Ventricular off-loading can be done by IV loop diuretics such as frusemide and vasodilation by NTG infusion at 5 to $10 \mu \mathrm{g} / \mathrm{min}$, titrated to the clinical condition and BP. Antenatal mothers with poor cardiac output and hypoperfusion will be benefited with exaggerated LUD to alleviate the aortocaval compression and may need an inotropic support. Patients with relative hypotension, who do not respond to vasodilators and diuretics, also benefit from the inotropic support. Inotropic agents improve cardiac contractility and cardiac output, increase renal perfusion and facilitate diuresis, preserve end-organ function, and promote clinical stability. ${ }^{12}$ Urine output monitored every hour acts as a surrogate for cardiac output monitoring. Those in refractory shock may benefit from temporary circulatory support with either intra-aortic balloon counter-pulsation or extracorporeal membrane oxygenation. ${ }^{12,13}$ Implantation of a left ventricular assist device (LVAD) is also described in PPCM either as a bridge to recovery or transplantation..$^{13}$ Fetal heart rate monitoring with CTG or ultrasound establishes the fetal well-being. Stabilization of the mother's condition is crucial than resorting to emergency cesarean delivery, which carries a higher maternal morbidity and mortality. Maternal stabilization can prevent or revert the fetal compromise. Pregnant women with PPCM and an EF of less than $35 \%$ are prone for $L V$ thrombus and need thromboprophylaxis with LMWH. ${ }^{14}$ ACE-I can be given postpartum. $\beta$-Blockers are protective against tachyarrhythmias and can improve survival. Bromocriptine, $2.5 \mathrm{mg}, 7$ to 14 days showed promising results in PPCM. ${ }^{15}$ Cabergoline, a potent dopamine receptor antagonist, has long half-life of 14 to 21 days and may be given as a single dose. ${ }^{16}$ Approximately $14 \%$ of PPCM women may need cardiac transplantation. ${ }^{12}$

\section{Anesthetic Considerations}

Anesthetic management of the PPCM patient includes preoperative optimization, intraoperative management, and postoperative stabilization. Both general and regional anesthesia can be given. Anesthetic technique depends on the urgency of delivery and the patient's hemodynamic stability. Vaginal delivery may be allowed 
with effective labor analgesia. Labor epidural analgesia decreases the sympathetic stimulation and decreases plasma catecholamine levels in the mother. ${ }^{17}$ The second stage of labor should be cut short with assisted vaginal delivery (forceps or vacuum), to reduce workload on the myocardium.

The anesthetic goal is to optimize cardiac output by maintaining the preload and decreasing the afterload. Myocardial contractility should be maintained by avoiding drugs that can decrease the already compromised cardiac contractility. Subarachnoid block and rapid induction of general anesthesia can result in precipitous fall in systemic vascular resistance and should be avoided. Incremental epidural dosing has been used in patients posted for nonemergent cesarean section with relatively stable hemodynamic status. ${ }^{18}$ General anesthesia is preferred in category 1 cesarean sections, in conditions of severe cardiac decompensation where even minor sympathetic blockade may lead to fulminant cardiac failure, and in anticoagulated patients. The associated problems are the rapid fall in the systemic vascular resistance, intrinsic difficult airway associated with pregnancy, and laryngosympathetic response during intubation and extubation. ${ }^{19}$ Undue reduction in the preload may worsen the fall in the cardiac output, whereas the decrease in afterload can compromise the coronary perfusion. Opioid-based cardiac induction provides good hemodynamic control and suppresses the laryngosympathetic response. Opioid induction has to be used judiciously as it may not be ideal for rapid-sequence induction and cause neonatal respiratory depression. Remifentanil infusion can alleviate some of these problems. ${ }^{20}$

Regional anesthesia techniques can be a better alternative. Incremental epidural, combined spinal epidural (CSE) ${ }^{21}$ and continuous spinal anesthesia (CSA) have been used in PPCM patients..$^{22}$ In patients on anticoagulant therapy, insertion and removal of neuraxial catheter should be planned according to the timing of anticoagulation administration. The advantage of incremental epidural is that it gives freedom of titrating the local anesthetic dose to achieve the desired level of motor and sensory block without causing sudden hypotension and decompensation in these patients. Regional anesthesia can decrease the cardiac preload and afterload and lead to an improvement in cardiac function. There is decrease in POPCs with regional techniques. A working epidural gives good postoperative pain relief.

Left uterine displacement is advocated to avoid aortocaval compression. Prophylactic infusion of phenylephrine can be used to maintain BPs without causing tachycardia. IV fluids should be titrated to maintain the hemodynamic stability without excessive preloading. Oxytocic drugs should be used with caution. Bolus or rapid infusion of oxytocin can cause a marked decrease in systemic vascular resistance, and in higher doses, it has an antidiuretic effect. ${ }^{23}$ Ergometrine should not be used as it causes significant increases in afterload and coronary vasospasm. Intramuscular injection of 15 methyl prostaglandin F2 alpha can be given but should be avoided in reactive airways. ${ }^{23} \mathrm{PGE}_{1}$ can be used as rectal suppository or sublingual dose. It can cause increased temperature and shivering.
Postpartum care should be in the ICU. The intraoperative cardiac monitoring should be continued in the postoperative period. Analgesia can be provided by epidural catheter or IV opioids or by transversus abdominis plane (TAP) block. Postoperative care includes spironolactone, ACE-I, $\beta$-blocker, fluid restriction, input-output chart, POPC protocol, and DVT prophylaxis with LMWH.

Early referral of patients with previous PPCM; multidisciplinary approach with early involvement of the obstetrician, cardiologist, and anesthetist; and planning of anesthesia and preoperative care can decrease the maternal mortality and morbidity in PPCM. Careful selection of anesthesia technique, meticulous hemodynamic monitoring, and slow and cautious titration of anesthetic drugs can improve the maternal and fetal outcome in this rare cardiomyopathy.

\section{Conclusion}

Peripartum cardiomyopathy is a rare condition and affects women in the third trimester (after 36weeks of pregnancy) and up to 5 months after delivery. Early diagnosis, continued monitoring, and prompt treatment of HF can decrease the maternal morbidity and mortality. Women with suspected PPCM, or a past history of PPCM, should be reviewed by a multidisciplinary team of an anesthesiologist, cardiologist, obstetrician, and neonatologist, and a plan should be made for mode of labor, delivery, and postpartum care. Incremental epidural dosing can be used in patients posted for nonemergency cesarean section, and it has the advantage of stable hemodynamic status without the risks associated with general anesthesia.

\section{Public Title}

To analyze the clinical features of PPCM at the time of presentation and to enumerate the plan of anesthesia and how to manage the patient in the immediate postoperative period for the good outcome of the mother and the child.

\section{Centre of Study}

Department of Anaesthesia, MGMH Petlaburz, Osmania Medical College, Hyderabad, India.

\section{Source(s) of Support}

None.

\section{Conflicts of Interest}

None.

\section{Authors' Contribution}

Mellacheruvu Sree Rama Chandra Murthy-conception, design, and writing of manuscript

Kousalya Chakravarthy (corresponding author)-conception, design, implementation, data collection, and interpretation of results, writing of manuscript Khaliq Ahmed-writing of manuscript

\section{Acknowledgment}

None.

\section{Note}

It was presented as podium presentation at Telangana State Conference of Anaesthesiologists at Narketpalley, Nalgonda, Telangana, India, on July 28, 2018. 


\section{References}

1 Sliwa K, Hilfiker-Kleiner D, Petrie MC, et al; Heart Failure Association of the European Society of Cardiology Working Group on Peripartum Cardiomyopathy. Current state of knowledge on aetiology, diagnosis, management, and therapy of peripartum cardiomyopathy: a position statement from the Heart Failure Association of the European Society of Cardiology Working Group on peripartum cardiomyopathy. Eur J Heart Fail 2010;12(8):767-778

2 Tidswell M. Peripartum cardiomyopathy. Crit Care Clin 2004;20(4):777-788, xi

3 Elkayam U, Akhter MW, Singh H, et al. Pregnancyassociated cardiomyopathy: clinical characteristics and a comparison between early and late presentation. Circulation 2005;111(16):2050-2055

4 Mishra TK, Swain S, Routray SN. Peripartum cardiomyopathy. Int J Gynaecol Obstet 2006;95(2):104-109

5 Hopkins TJ, Raghunathan K, Barbeito A, et al. Associations between ASA physical status and postoperative mortality at $48 \mathrm{~h}$ : a contemporary dataset analysis compared to a historical cohort. Perioper Med (Lond) 2016;5:29

6 Joint Commission. Specifications Manual for Joint Commission National Quality Measures (v2016A). 2016. Available at: https://manual.jointcommission.org/releases/TJC2016A/ DataElem0439.html Accessed July 16, 2016

7 Regitz-Zagrosek V, Blomstrom Lundqvist C, Borghi C, et al; European Society of Gynecology (ESG); Association for European Paediatric Cardiology (AEPC); German Society for Gender Medicine (DGesGM); ESC Committee for Practice Guidelines. ESC Guidelines on the management of cardiovascular diseases during pregnancy: the Task Force on the Management of Cardiovascular Diseases during Pregnancy of the European Society of Cardiology (ESC). Eur Heart J 2011;32(24):3147-3197

8 Ersbøll AS, Damm P, Gustafsson F, Vejlstrup NG, Johansen M. Peripartum cardiomyopathy: a systematic literature review. Acta Obstet Gynecol Scand 2016;95(11):1205-1219

9 Azibani F, Sliwa K. Peripartum cardiomyopathy: an update. Curr Heart Fail Rep 2018;15(5):297-306

10 Kim M-J, Shin M-S. Practical management of peripartum cardiomyopathy. Korean J Intern Med (Korean Assoc Intern Med) 2017;32(3):393-403

11 Baruteau AE, Leurent G, Martins RP, et al. Peripartum cardiomyopathy in the era of cardiac magnetic resonance imaging: first results and perspectives. Int J Cardiol 2010;144(1):143-145
12 Johnson-Coyle L, Jensen L, Sobey A; American College of Cardiology Foundation; American Heart Association. Peripartum cardiomyopathy: review and practice guidelines. Am J Crit Care 2012;21(2):89-98

13 Hilfiker-Kleiner D, Haghikia A, Nonhoff J, Bauersachs J. Peripartum cardiomyopathy: current management and future perspectives. Eur Heart J 2015;36(18):1090-1097

14 Lata I, Gupta R, Sahu S, Singh H. Emergency management of decompensated peripartum cardiomyopathy. J Emerg Trauma Shock 2009;2(2):124-128

15 Hilfiker-Kleiner D, Haghikia A, Berliner D, et al. Bromocriptine for the treatment of peripartum cardiomyopathy: a multicentre randomized study. Eur Heart J 2017;38(35):2671-2679

16 de Jong JS, Rietveld K, van Lochem LT, Bouma BJ. Rapid left ventricular recovery after cabergoline treatment in a patient with peripartum cardiomyopathy. Eur J Heart Fail 2009;11(2):220-222

17 Ray P, Murphy GJ, Shutt LE. Recognition and management of maternal cardiac disease in pregnancy. $\mathrm{Br} \mathrm{J}$ Anaesth 2004;93(3):428-439

18 George LM, Gatt SP, Lowe S. Peripartum cardiomyopathy: four case histories and a commentary on anaesthetic management. Anaesth Intensive Care 1997;25(3):292-296

19 Kaufman I, Bondy R, Benjamin A. Peripartum cardiomyopathy and thromboembolism; anesthetic management and clinical course of an obese, diabetic patient. Can J Anaesth 2003;50(2):161-165

20 McCarroll CP, Paxton LD, Elliott P, Wilson DB. Use of remifentanil in a patient with peripartum cardiomyopathy requiring caesarean section. Br J Anaesth 2001;86(1):135-138

21 Shnaider R, Ezri T, Szmuk P, Larson S, Warters RD, Katz J. Combined spinal-epidural anesthesia for cesarean section in a patient with peripartum dilated cardiomyopathy. Can J Anaesth 2001;48(7):681-683

22 Velickovic IA, Leicht $\mathrm{CH}$. Continuous spinal anesthesia for cesarean section in a parturient with severe recurrent peripartum cardiomyopathy. Int $\mathrm{J}$ Obstet Anesth 2004;13(1):40-43

23 Ramachandran R, Rewari V, Trikha A. Anaesthetic management of patients with peripartum cardiomyopathy. J Obstet Anaesth Crit Care 2011;1(1):5-12 